\title{
Periodic Doubling and Chaotic Attractor in the Love Model with a Fourier Series Function as External Force
}

\section{]jfis}

\section{Linyun Huang ${ }^{1}$ and Youngchul Bae ${ }^{2}$}

${ }^{1}$ Department of Biomedical and Electronic Engineering, Chonnam National University, Yeosu, Korea

${ }^{2}$ Electrical-Electronic Communication and Computer Engineering, Chonnam National University, Yeosu, Korea

\begin{abstract}
This paper propose a dynamic mathematical model of love with the Fourier series function as an external force. We also investigate the periodic doubling including 1, 2, 4 periodic motion, chaotic attractor and limit cycle in the love models based on Romeo and Juliet with the Fourier series function as an external force, using time series and phase portraits. To show the nonlinear phenomena using time series and phase portraits, we vary the parameter value with the Fourier series function as an external force.
\end{abstract}

Keywords: Chaotic phenomena, Nonlinear dynamic, Love model, Time series, Phase portrait, External force, Fourier series function

\section{Introduction}

In general, the human society can model as a complex system. Typically, complex systems have the characteristics of a nonlinear dynamical system, which can describe by a differential equation or difference equation. However, when we compare with linear systems, nonlinear systems are more difficult to analyze, synthesize, implement or design. All natural systems in the world or earth such as wind, weather, and human behavior are nonlinear systems, which include fuzzy systems, neural networks, chaotic systems, and complex systems. Among these nonlinear systems, chaotic systems have gained considerable interest over the last three decades among many researches in the field of mathematics, physics, chemistry, engineering, and social science.

In particular, studies on chaotic behaviors in the social sciences, including those related to Revised : Mar. 22, 2017 Accepted: Mar. 22, 2017

Correspondence to: Youngchul Bae (ycbae@chonnam.ac.kr)

(OThe Korean Institute of Intelligent Systems

(C)This is an Open Access article distributed under the terms of the Creative Commons Attribution Non-Commercial License (http://creativecommons.org/licenses/ by-nc/3.0// which permits unrestricted noncommercial use, distribution, and reproduction in any medium, provided the original work is properly cited. habits and the human mind, such as addiction [1-4], happiness [5- 8], physical exercise [27] and love models [8-13], involve an overlap of the fields of mathematics, biology, psychology, and social science.

Bae and his associates [1-4] and Kim [27] proposed a mathematical model for addictions to digital leisure, internet, tobacco, and physical exercise. Further, they also verified the presence of nonlinear behaviors or chaotic phenomena by using time series and phase portraits.

Sprott [6, 8] proposed a basic dynamic equation for happiness and investigated its behavior. Bae [7] proposed a mathematical happiness model and a synchronization technique for the model.

Love model have proposed several models including the Romeo and Juliet model [9-13], the Laura and Petrarch model [14, 15], the Adam and Eve model [16], and others [17,-21]. 
Among these, the Romeo and Juliet's love model is most commonly use in the research of nonlinear dynamics and complex systems.

Strogatz [21, 22] was the first to suggest modelling love affairs by using differential equations; for example, a simple model for the ill-fated romance of Romeo and Juliet modelled as a second-linear system. He also defined love affairs according to parameter values.

Sprott [8] who is inspired by Strogatz's research [21, 22], proposed a love model based on Romeo and Juliet, which was represented by the linear differential equation; Sprott also described the linear as well as nonlinear behaviors of the model.

The existence of periodic motion and chaotic behavior or motion in the love model based on Romeo and Juliet is represented through time series and phase portraits, with either the same or different time delays, an external force, and different external forces proposed by Bae [16-21, 25, 26].

Bae and his associates recently proposed external force that compose fuzzy membership function such as Gaussian [28, 29], triangular [30], which close to represent human mind. They shows chaotic behavior according to varying parameter value.

However, most previously published papers in the love model of Romeo and Juliet, sufficiently have not provided to represent human mind through an time series or phase portrait to demonstrate chaotic phenomena or behavior, including periodic motion.

In this paper, we propose a dynamic mathematical model of love with the Fourier series function as an external force. We also investigate the chaotic behaviors including periodic doubling in the love models based on Romeo and Juliet with the Fourier series function as an external force based on varying the parameter value using time series and phase portraits.

\section{Love Model}

There are many love models for Romeo and Juliet; we can classify these models as follows:

\subsection{Basic Love Model}

Strogatz [21, 22] and Sprott [15] proposed the basic love model for Romeo and Juliet, which can formulate as

$$
\begin{aligned}
& \frac{\mathrm{dR}}{\mathrm{dt}}=\mathrm{aR}+\mathrm{bJ}, \\
& \frac{\mathrm{dJ}}{\mathrm{dt}}=\mathrm{cR}+\mathrm{dJ},
\end{aligned}
$$

where parameter a, and b specify Romeo's romantic style, and c and d specify Juliet's style.

\subsection{Alternative Love Model}

Sprott [8] also proposed an alternative love model for Romeo and Juliet, which can be written as

$$
\begin{aligned}
& \frac{\mathrm{dR}}{\mathrm{dt}}=\mathrm{aR}+\mathrm{bJ}(1-|\mathrm{J}|), \\
& \frac{\mathrm{dJ}}{\mathrm{dt}}=\mathrm{cR}(1-|\mathrm{R}|)+\mathrm{dJ},
\end{aligned}
$$

Where, parameter a, b, c and d are same to use for the basic love model.

\subsection{Alternative Love Model with an External Force}

(1) and (2) cannot shows the chaotic phenomena, because these equations have second-order systems. To make chaotic phenomena in a dynamic model, the model must involve a third-order system, and it must contain at least one nonlinear term. Because (1) and (2) for the love model of Romeo and Juliet do not satisfy the necessary conditions for a third-order system, they have to modify to satisfy the condition. Bae [16] proposed an alternative love model, which involves external forces, can be written as

$$
\begin{aligned}
& \frac{\mathrm{dR}}{\mathrm{dt}}=\mathrm{aR}+\mathrm{bJ}(1-|\mathrm{J}|)+f(t), \\
& \frac{\mathrm{dJ}}{\mathrm{dt}}=\mathrm{cR}(1-|\mathrm{R}|+\mathrm{dJ}),
\end{aligned}
$$

or

$$
\begin{aligned}
& \frac{\mathrm{dR}}{\mathrm{dt}}=\mathrm{aR}+\mathrm{bJ}(1-|\mathrm{J}|), \\
& \frac{\mathrm{dJ}}{\mathrm{dt}}=\mathrm{cR}(1-|\mathrm{R}|+\mathrm{dJ}+\mathrm{y}(\mathrm{t})),
\end{aligned}
$$

or

$$
\begin{aligned}
& \frac{\mathrm{dR}}{\mathrm{dt}}=\mathrm{aR}+\mathrm{bJ}(1-|\mathrm{J}|)+f(t), \\
& \frac{\mathrm{dJ}}{\mathrm{dt}}=\mathrm{cR}(1-|\mathrm{R}|+\mathrm{d} \mathrm{J}+\mathrm{y}(\mathrm{t})),
\end{aligned}
$$

where $\mathrm{f}(\mathrm{t})$ and $\mathrm{y}(\mathrm{t})$ are external forces applied to the Romeo and Juliet differential equations, respectively.

Authors [24, 25] demonstrated the existence of chaotic phenomena when $\mathrm{f}(\mathrm{t})=\sin \omega \mathrm{t}$ and $\mathrm{y}(\mathrm{t})=0$ in $(3), \mathrm{f}(\mathrm{t})=0$ and $\mathrm{y}(\mathrm{t})=\sin \omega \mathrm{t}$ in (4), and $\mathrm{f}(\mathrm{t})=\sin \omega \mathrm{t}$ and $\mathrm{y}(\mathrm{t})=\sin \omega \mathrm{t}$ in (5), using time series and phase portraits, which include 


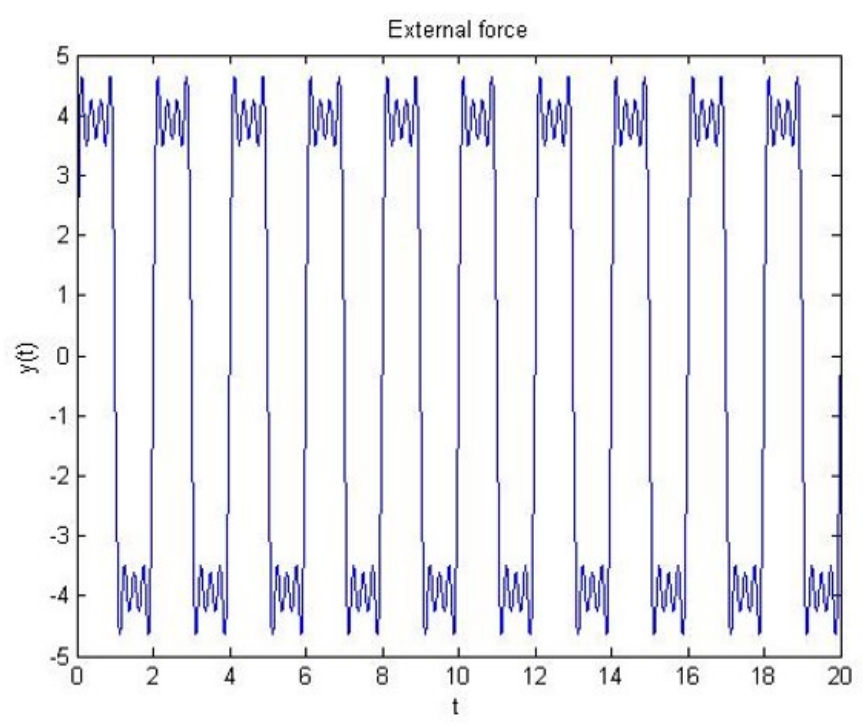

Figure 1. Fourier series function.

periodic motions and chaotic attractors.

\section{Chaotic Behaviors in Love Model with Fourier Series Function as an External Force}

In this paper, we consider the chaotic behaviors in (3), (4), and (5) with the Fourier series as an external force using computer simulation with MATLAB. In addition, we apply different parameters for (3), (4), and (5). Equation (6) represents the Fourier series function that use as an external force, and Figure 1 shows its time series.

$$
\mathrm{f}(\mathrm{t})=5\left(\sin \pi t+\frac{1}{3} \sin 3 \pi t+\frac{1}{5} \sin 5 \pi t+\frac{1}{7} \sin 7 \pi t \cdots\right)
$$

In the following section, the time series and phase portrait for (4) are reviewed with different parameter values; in different cases when external force is applied as a Fourier series function. The parameter $\mathrm{b}, \mathrm{c}$, and $\mathrm{d}$ are fixed as $-2,1$, and 1 , respectively. When parameter a varied from -7 from 12 , time series and phase portrait get following as.

\subsection{Case from $\mathrm{a}=-7$ to $\mathrm{a}=-5.6$}

First, we investigate the time series and phase portrait to show the behavior of love for Romeo and Juliet, when we set the parameters "a" from -7 to -5.6 in (4), which has the characteristics of an alternative love model. Figure 2 illustrates the results of the time series and phase portrait, when the parameter "a" have -7 in (4) that are applied for Juliet's item with Fourier
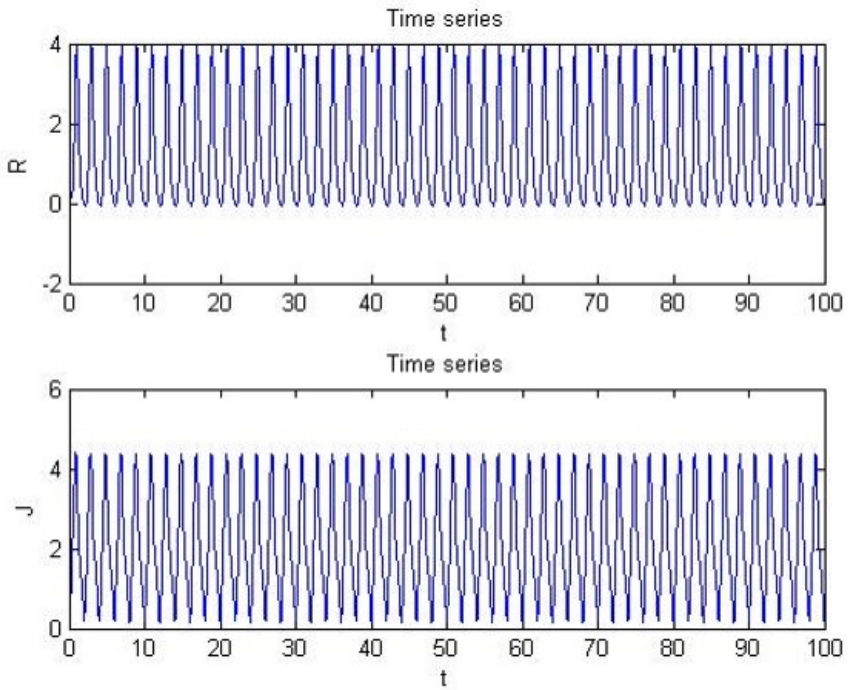

(a)

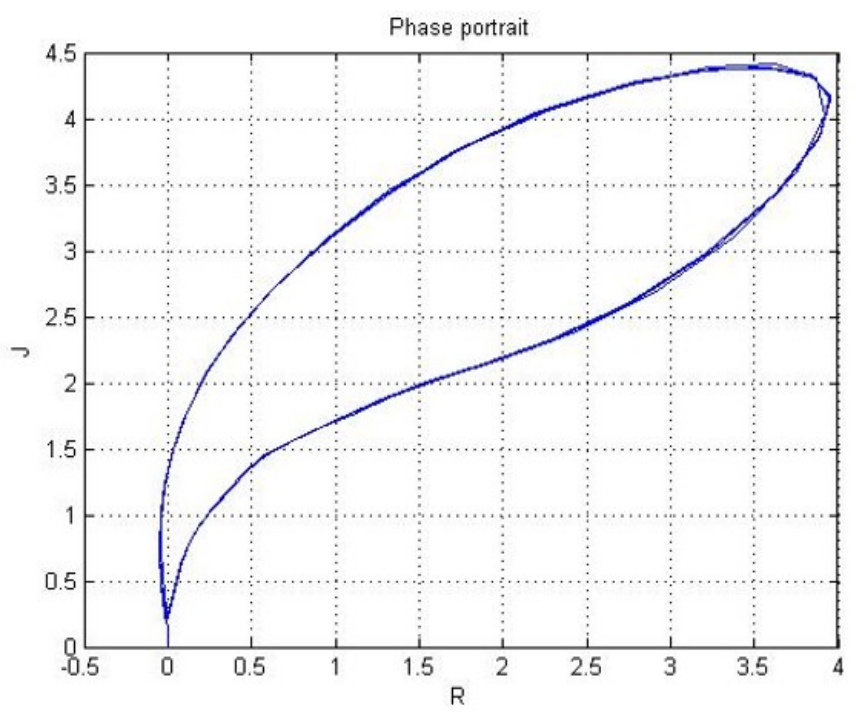

(b)

Figure 2. Results of time series (a) and phase portrait (b) when (4) apply with $\mathrm{a}=-6.5, \mathrm{~b}=-2, \mathrm{c}=1$, and $\mathrm{d}=1$ parameters.

series function as an external forces. From Figure 2, we recognize that this is 1-periodic motion. 1-periodic motion maintain until $\mathrm{a}=-5.6$.

\subsection{Case $\mathrm{a}=-5.5$}

We investigate the time series and phase portrait to show the behavior of love for Romeo and Juliet when we set the parameters as $\mathrm{a}=-5.5, \mathrm{~b}=-2, \mathrm{c}=1$, and $\mathrm{d}=1$ in (4). Figure 3 shows the results of the time series and phase portrait. We know that Figure 3 represents 2 -periodic motion and its motion continue 

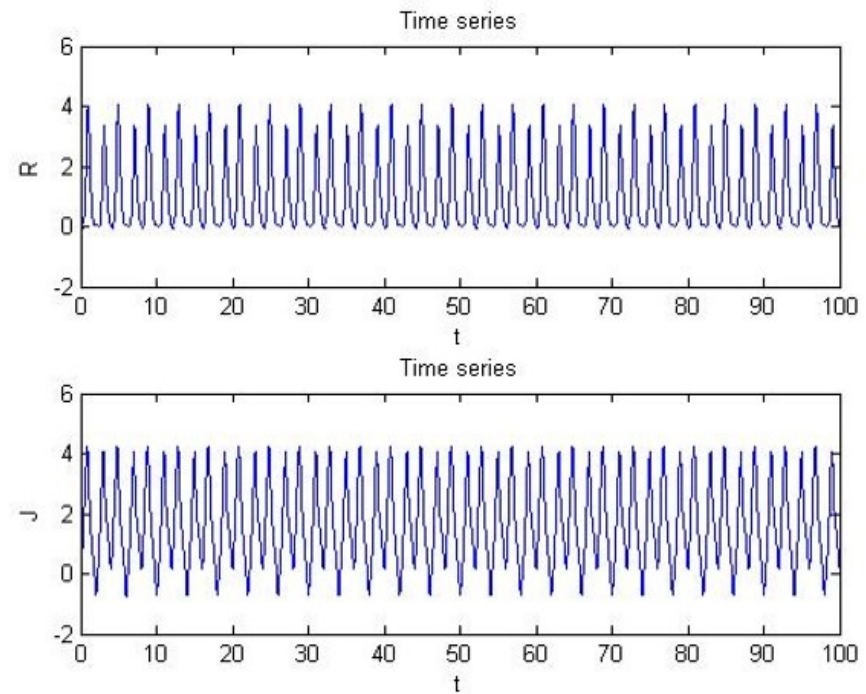

(a)

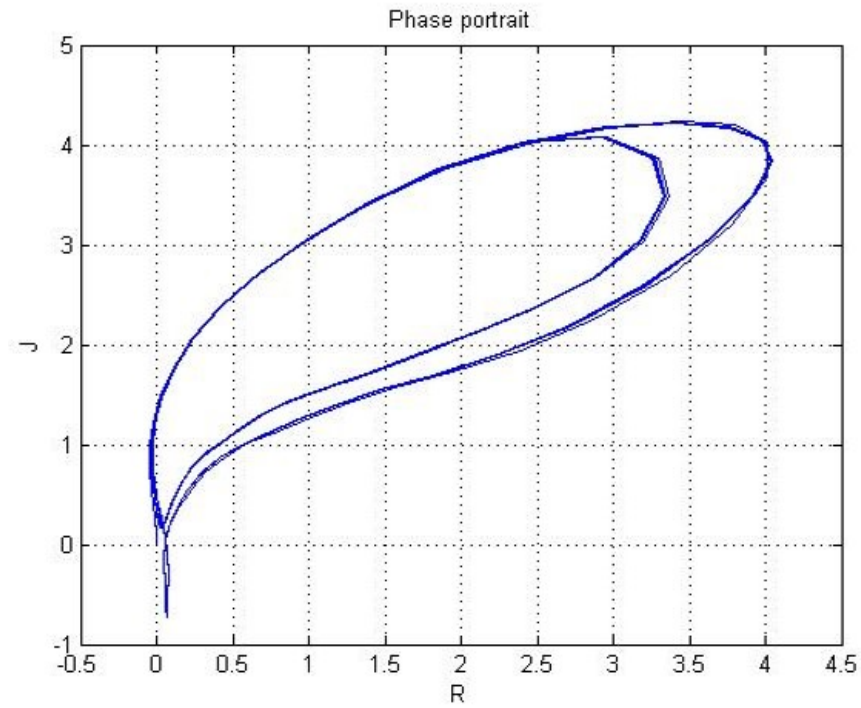

(b)

Figure 3. Results of time series (a) and phase portrait (b) when (2) apply with $\mathrm{a}=-5.5, \mathrm{~b}=-2, \mathrm{c}=1$, and $\mathrm{d}=1$ parameters.

to until $\mathrm{a}=-5.1$.

\subsection{Case $\mathrm{a}=-5$}

We now investigate the time series and phase portrait to show the behavior of love for Romeo and Juliet when we set the parameters as $\mathrm{a}=-5, \mathrm{~b}=-2, \mathrm{c}=1$, and $\mathrm{d}=1$ in (4). Figure 4 illustrates the results of the time series and phase portrait with these parameters. From Figure 4, we know it has 4-periodic motion. We also see from Figures 2-4 that these figures progress
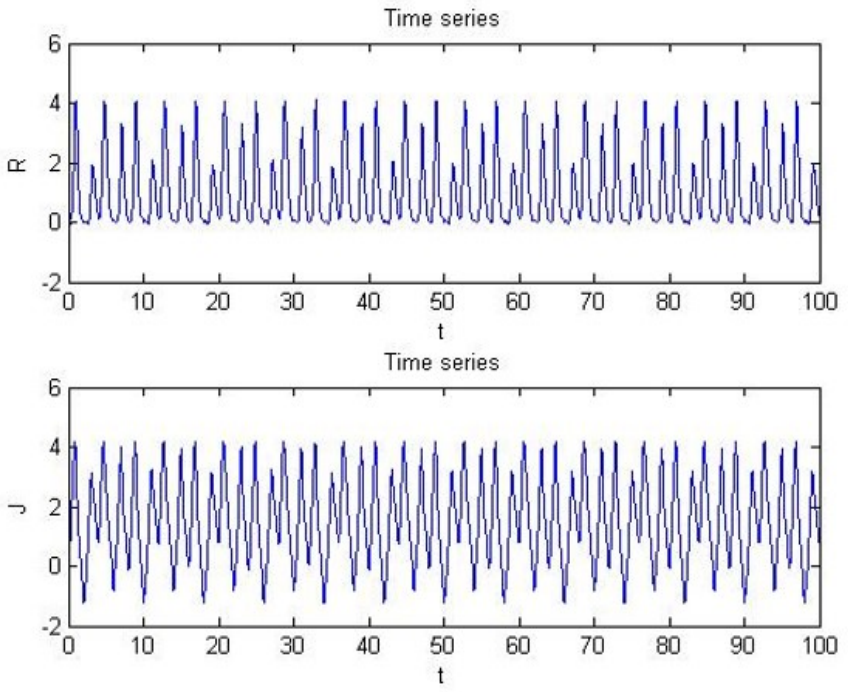

(a)

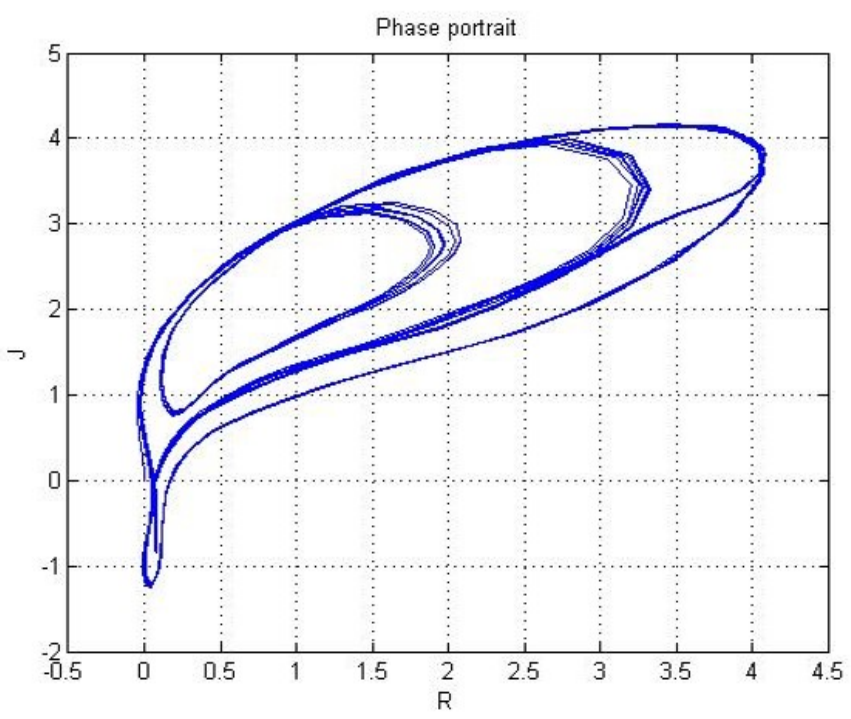

(b)

Figure 4. Results of time series (a) and phase portrait (b) when (2) apply with $\mathrm{a}=-5.0, \mathrm{~b}=-2, \mathrm{c}=1$, and $\mathrm{d}=1$ parameters.

periodic motion of $1,2,4$, which is called periodic doubling that take place typically before chaotic motion. Therefore, we can expect that chaotic attractor appear next parameter value.

\subsection{Case $\mathrm{a}=-4.5$}

We now investigate the chaotic attractor to discover the nature of the chaotic phenomena, when we set the parameters as a $=$ $-4.5, \mathrm{~b}=-2, \mathrm{c}=1$, and $\mathrm{d}=1$, with the Fourier series function in (4). Figure 5 illustrates the results of the time series and phase portrait with these parameters. On comparing Figures 

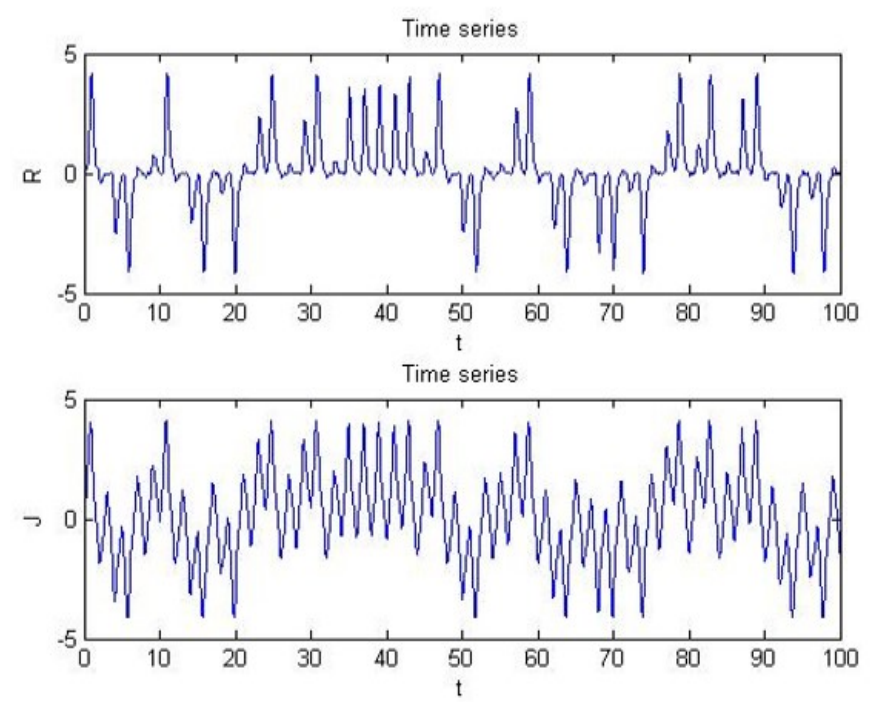

(a)

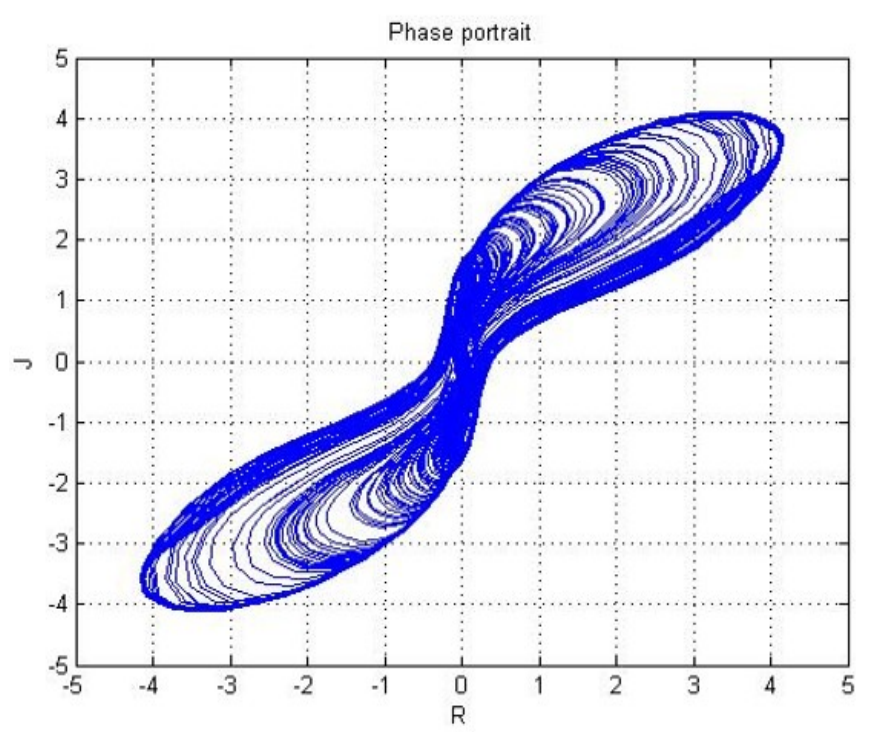

(b)

Figure 5. Results of time series (a) and phase portrait (b) when (2) apply with $\mathrm{a}=-4.5, \mathrm{~b}=-2, \mathrm{c}=1$, and $\mathrm{d}=1$ parameters.

4 and 5 , we recognize that there is a significant difference, one is periodic motion and the other is chaotic motion as varying different parameters.

Generally chaotic phenomena happens following as order: periodic motion, chaotic motion, periodic motion which is called periodic windows and limit cycle, or periodic motion, chaotic motion and limit cycle. Thus, we can also expect that two different way, periodic motion and chaotic attractor, and limit cycle occur when we apply another parameter value.

\subsection{Case $\mathrm{a}=-4$ and $\mathrm{a}=-3.5$}

We investigate that periodic motion or limit cycle take place when we set the parameters as $\mathrm{a}=-4, \mathrm{~b}=-2, \mathrm{c}=1$, and $\mathrm{d}=1$, with the Fourier series function in (4). Figures 6 and 7 illustrates the results of the time series and phase portrait with these parameters. From Figures 6 and 7, we know that these figures seems like periodic motion. In this case, the periodic motion cannot shows periodic doubling, they shows various periodic motion such as 3-periodic motion or quasi-periodic motion. Figure 6 shows simple periodic motion whereas Figure 7 shows quasi-periodic motion.

From result of Figures 5 and 6, we can easily expect that next parameter value shows the chaotic motion because of pattern according to order of periodic doubling, chaotic attractor, periodic window and limit cycle.

\subsection{Case $\mathrm{a}=-3.0$}

We investigate that periodic motion or limit cycle take place when we set the parameters as $\mathrm{a}=-3.0, \mathrm{~b}=-2, \mathrm{c}=1$, and $\mathrm{d}=1$, with the Fourier series function in (4).

From result of Figures 5 and 7, we recognize that the 2 chaotic attractors are little different.

\subsection{Case from $\mathrm{a}=-2.5$ to $\mathrm{a}=-1$}

We investigate the limit cycle when we set the parameters as $\mathrm{a}=-2.5, \mathrm{~b}=-2, \mathrm{c}=1$, and $\mathrm{d}=1$, with the Fourier series function in (47). Figure 8 shows the results of the time series and phase portrait with these parameters.

\section{Conclusions}

In this paper, we proposed a dynamic mathematical model of love with a Fourier series function as an external force. We also investigated the chaotic behaviors that have periodic doubling and chaotic attractor in love models of Romeo and Juliet with the Fourier series function as an external force, using time series and phase portraits. This paper shows that proposed dynamic mathematical model of love with a Fourier series function as an external force have chaotic behaviors including periodic doubling, chaotic attractor and limit cycle.

\section{Conflict of Interest}

No potential conflict of interest relevant to this article was reported. 

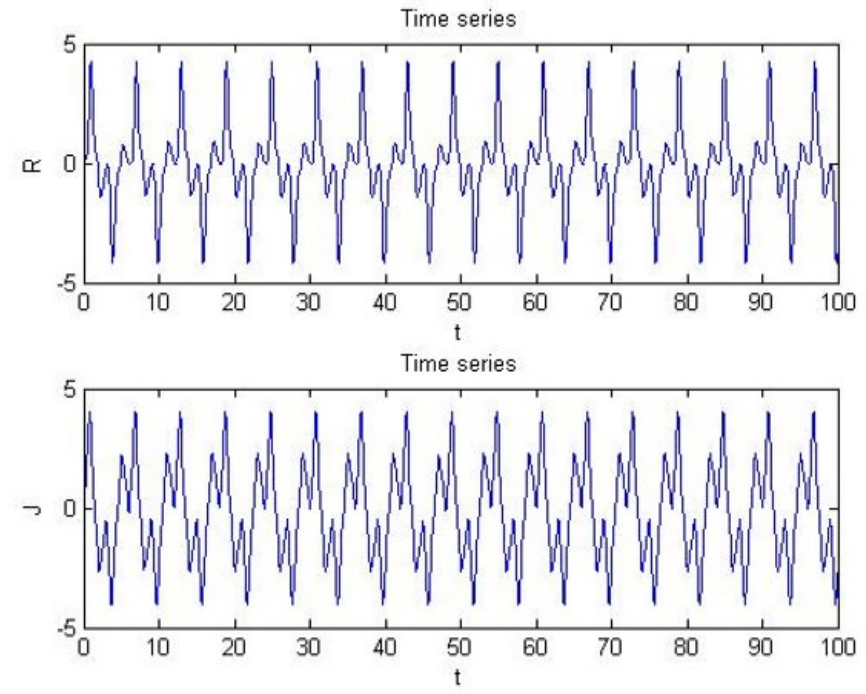

(a)

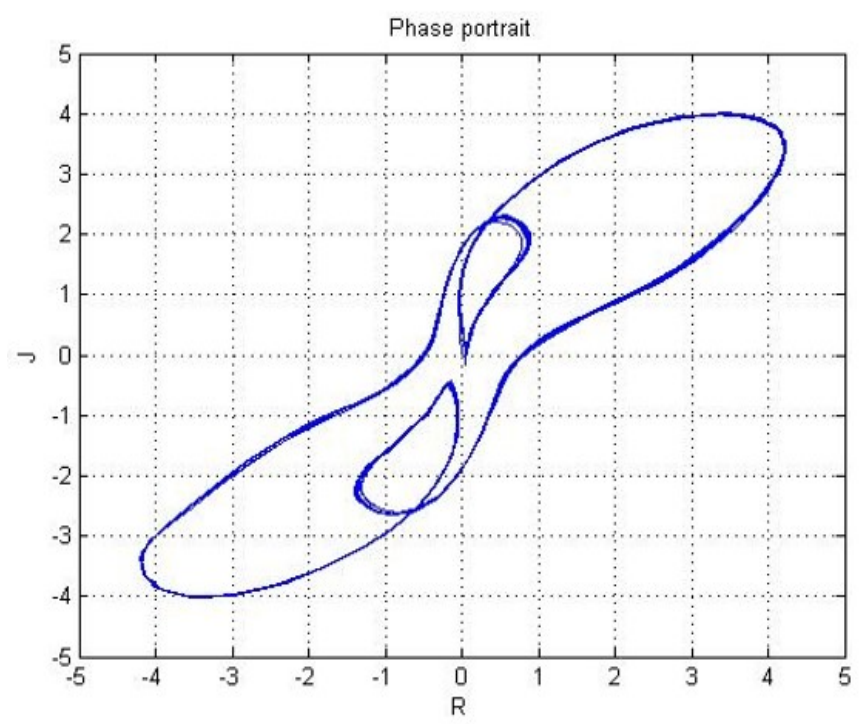

(b)

Figure 6. Results of time series (a) and phase portrait (b) when (2) apply with $\mathrm{a}=-4.0, \mathrm{~b}=-2, \mathrm{c}=1$, and $\mathrm{d}=1$ parameters.

\section{References}

[1] Y. Bae, "Chaotic phenomena in addiction model for digital leisure," International Journal of Fuzzy Logic and Intelligent Systems, vol. 13, no. 4, pp. 291-297, 2013. http://dx.doi.org/10.5391/IJFIS.2013.13.4.291

[2] M. M. Kim and Y. C. Bae, "Mathematical modelling and chaotic behavior analysis of cyber addiction," Journal of Korean Institute of Intelligent Systems, vol. 24, no. 3, pp.
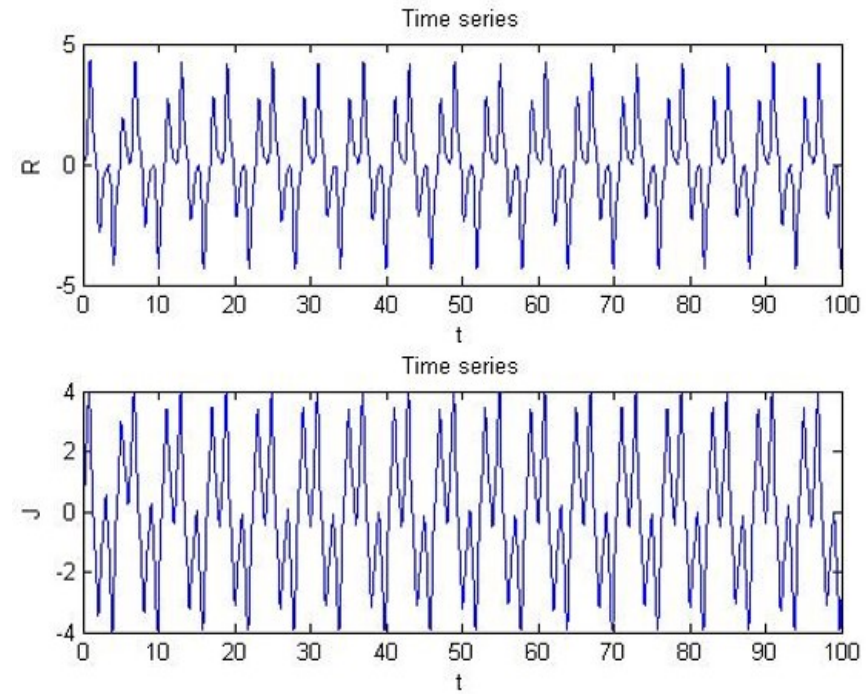

(a)

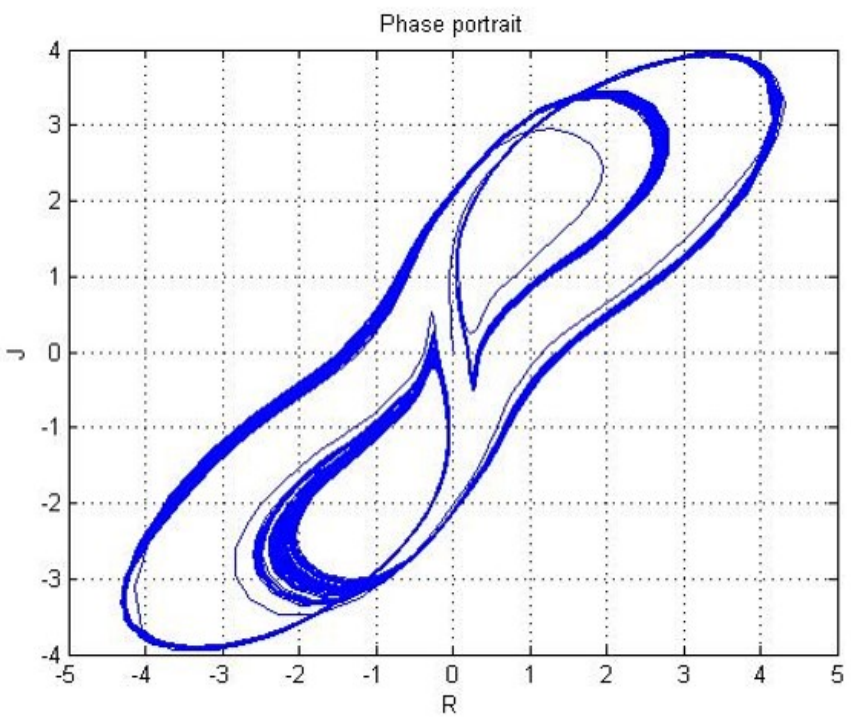

(b)

Figure 7. Results of time series (a) and phase portrait (b) when (2) apply with $\mathrm{a}=-3.5, \mathrm{~b}=-2, \mathrm{c}=1$, and $\mathrm{d}=1$ parameters.

245-250, 2014. http://dx.doi.org/10.5391/JKIIS.2014.24. 3.245

[3] Y. Bae, "Chaotic dynamics in tobacco's addiction model," International Journal of Fuzzy Logic and Intelligent Systems, vol. 14, no. 4, pp. 322-331, 2014. http://dx.doi.org/ 10.5391/IJFIS.2014.14.4.322

[4] Y. C. Bae, "Mathematical modelling and behavior analysis of addiction of physical exercise," Journal of Korean 

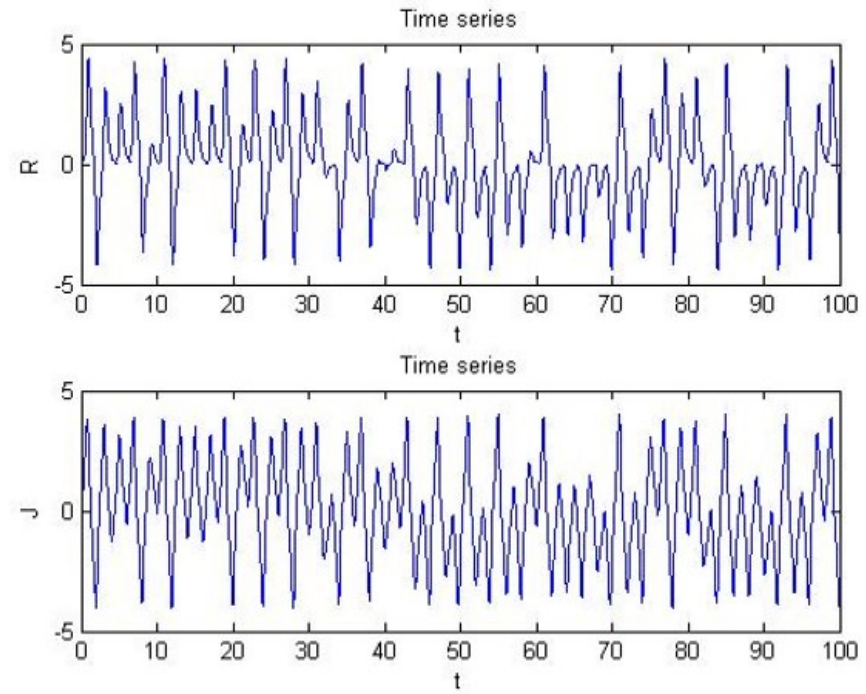

(a)

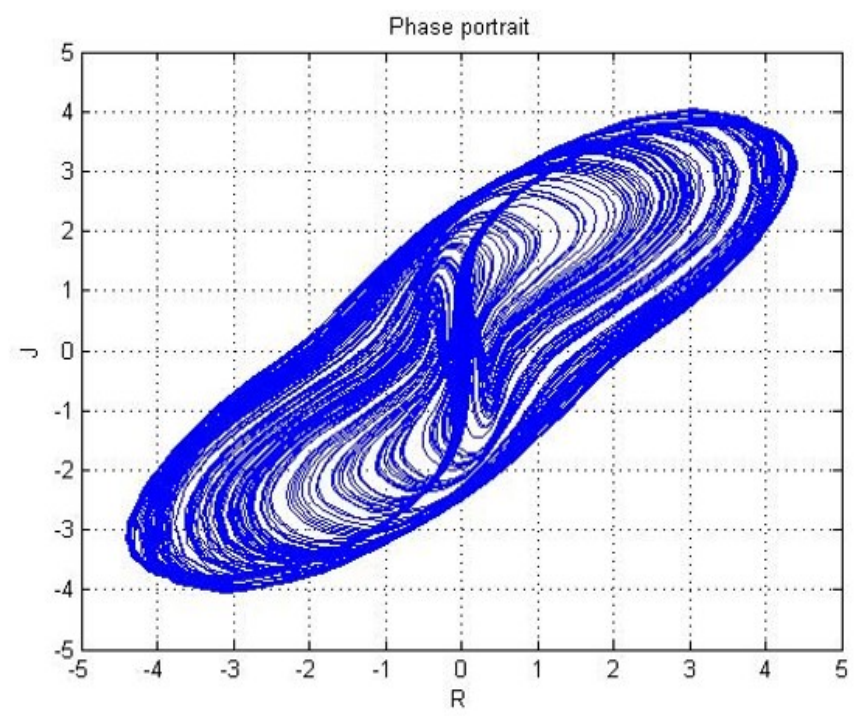

(b)

Figure 8. Results of time series (a) and phase portrait (b) when (2) apply with $\mathrm{a}=-3.0, \mathrm{~b}=-2, \mathrm{c}=1$, and $\mathrm{d}=1$ parameters.

Institute of Intelligent Systems, vol. 24, no. 6, pp. 615-621, 2014. http://dx.doi.org/10.5391/JKIIS.2014.24.6.615

[5] S. W. Kim, S. K. Choi, Y. C. Bae, and Y. H. Park, "Mathematical modelling of happiness and its nonlinear analysis," The Journal of the Korea Institute of Electronic Communication Sciences, vol. 9, no. 6, pp. 711-718, 2014. http://dx.doi.org/10.13067/JKIECS.2014.9.6.711

[6] J. C. Sprott, "Dynamical models of happiness," Nonlinear Dynamics, Psychology, and Life Sciences, vol. 9, no. 1, pp.
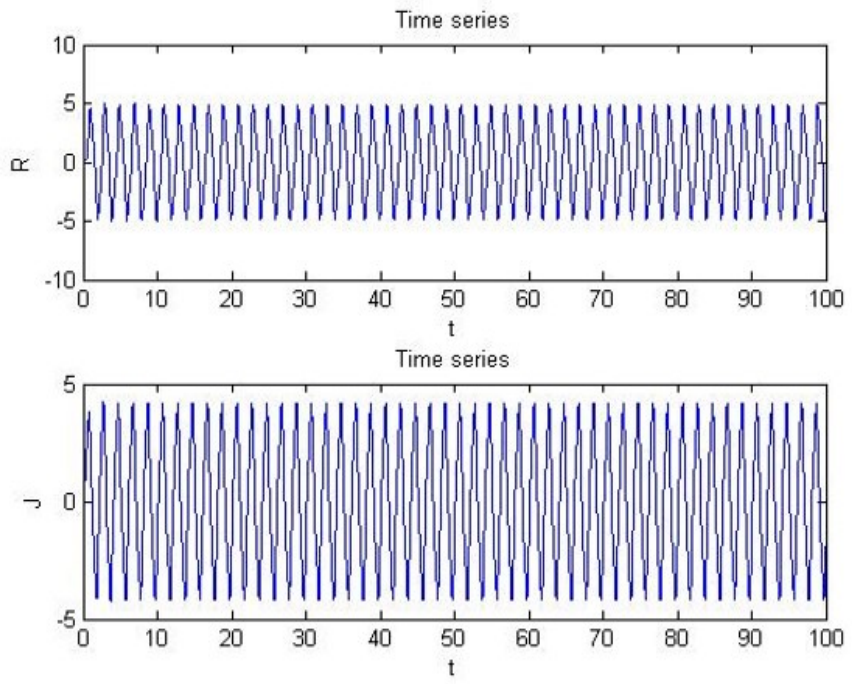

(a)

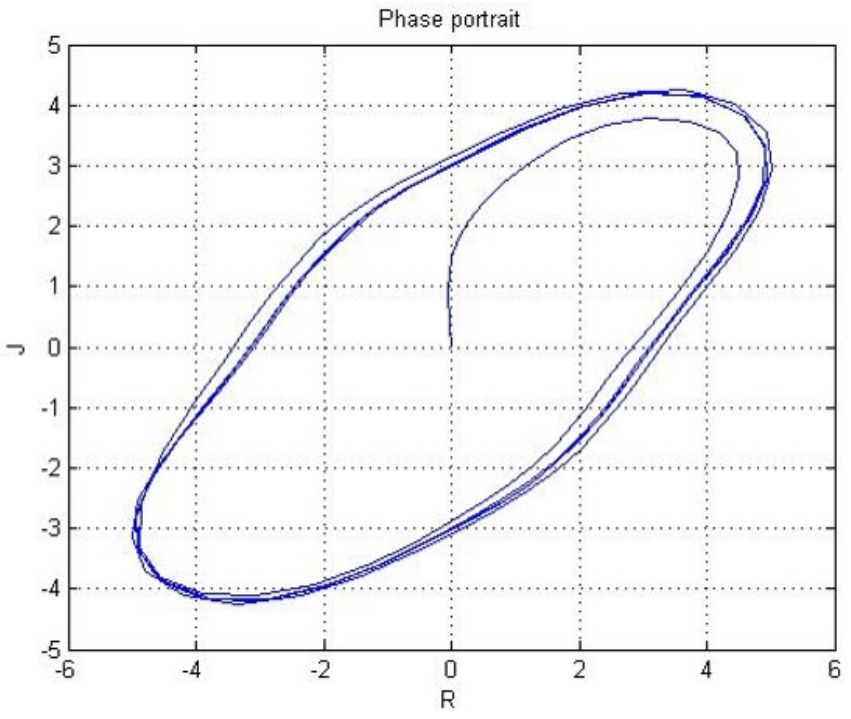

(b)

Figure 9. Results of time series (a) and phase portrait (b) when (2) apply with $\mathrm{a}=-2.5, \mathrm{~b}=-2, \mathrm{c}=1$, and $\mathrm{d}=1$ parameters.

\section{3-36, 2005.}

[7] Y. Bae, "Synchronization of dynamical happiness model," International Journal of Fuzzy Logic and Intelligent Systems, vol. 14, no. 2, pp. 91-97, 2014. http://dx.doi.org/10. 5391/IJFIS.2014.14.2.91

[8] J. C. Sprott, "Dynamics of love and happiness," in Proceedings of Chaos and Complex Systems Seminar, Madison, WI, 2001. 
[9] S. W. Kim, Y. W. Shon, and Y. C. Bae, "Mathematical modelling of love and its nonlinear analysis," The Journal of the Korea Institute of Electronic Communication Sciences, vol. 9, no. 11, pp. 1297-1304, 2014. http://dx.doi.org/10.13067/JKIECS.2014.9.11.1297

[10] Y. C. Bae, "Behavior analysis of dynamic love model with time delay," The Journal of the Korea Institute of Electronic Communication Sciences, vol. 10, no. 2, pp. 253-260, 2015. http://dx.doi.org/10.13067/JKIECS.2015. 10.2.253

[11] Y. C. Bae, "Modified mathematical modelling of love and its behaviour analysis," The Journal of the Korea Institute of Electronic Communication Sciences, vol. 9, no. 12, pp. 1441-1446, 2014. http://dx.doi.org/10.13067/JKIECS. 2014.9.12.1441

[12] L. Huang and Y. C. Bae, "Behavior analysis in love model of Romeo and Juliet with time delay," Journal of Korean Institute of Intelligent Systems, vol. 25, no. 2, pp. 155-160, 2015. http://dx.doi.org/10.5391/JKIIS.2015.25.2.155

[13] L. Huang and Y. C. Bae, "Comparative behavior analysis in love model with same and different time delay," Journal of Korean Institute of Intelligent Systems, vol. 25, no. 3, pp. 210-216, 2015. http://dx.doi.org/10.5391/JKIIS.2015. 25.3.210

[14] S. H. Strogatz, "Love affairs and differential equations," Mathematics Magazine, vol. 61, no. 1, pp. 35, 1988. http: //dx.doi.org/10.2307/2690328

[15] S. H. Strogatz, Nonlinear Dynamics and Chaos: With Applications to Physics, Biology, Chemistry, and Engineering. Reading, MA: Addison-Wesley, 1994.

[16] S. Rinaldi, "Laura and Petrarch: an intriguing case of cyclical love dynamics," SIAM Journal on Applied Mathematics, vol. 58, no. 4, pp. 1205-1221, 1998. http://dx.doi. org/10.1137/S003613999630592X

[17] F. Breitenecker, F. Judex, N. Popper, K. Breitenecker, A. Mathe, and A. Mathe, "Love emotions between Laura and Petrarch: an approach by mathematics and system dynamics," Journal of Computing and Information Technology, vol. 16, no. 4, pp. 255-269, 2008. http://dx.doi. org/10.2498/cit.1001393
[18] J. M. Rey, "Optimal control of long-term sentimental dynamics," in Proceedings of Modelling for Engineering \& Human Behaviour 2011, Valencia, Spain, 2011, pp. 274-278.

[19] C. Cresswell, Mathematics and Sex. Sydney: Allen \& Unwin, 2003.

[20] J. Wauer, D. Schwarzer, G. Q. Cai, and Y. K. Lin, "Dynamical models of love with time-varying fluctuations," Applied Mathematics and Computation, vol. 188, no. 2, pp. 1535-1548, 2007. http://dx.doi.org/10.1016/j.amc.2006. 11.026

[21] S. Rinaldi, "Love dynamics: the case of linear couples," Applied Mathematics and Computation, vol. 95, no. 23, pp. 181-192, 1998. http://dx.doi.org/10.1016/S00963003(97)10081-9

[22] X. Liao and J. Ran, "Hopf bifurcation in love dynamical models with nonlinear couples and time delays," Chaos, Solitons \& Fractals, vol. 31, no. 4, pp. 853-865, 2007. http://dx.doi.org/10.1016/j.chaos.2005.10.037

[23] W. M. Ahmad and R. El-Khazali, "Fractional-order dynamical models of love," Chaos, Solitons \& Fractals, vol. 33, no. 4, pp. 1367-1375, 2007. http://dx.doi.org/10.1016/ j.chaos.2006.01.098

[24] L. U. Huang and Y. C. Bae, "Analysis of nonlinear behavior in love model with external force," The Journal of the Korea Institute of Electronic Communication Sciences, vol. 10, no. 7, pp. 845-850, 2015. http://dx.doi.org/ 10.13067/JKIECS.2015.10.7.845

[25] Y. Bae, "Chaotic behavior in a dynamic love model with different external forces," International Journal of Fuzzy Logic and Intelligent Systems, vol. 15, no. 4, pp. 283-288, 2015. http://dx.doi.org/10.5391/IJFIS.2015.15.4.283

[26] W. Liu and K. Chen, "Chaotic behavior in a new fractionalorder love triangle system with competition," Journal of Applied Analysis and Computation, vol. 5, no. 1, pp. 103113, 2015. http://dx.doi.org/10.11948/2015009

[27] M. M. Kim, "Analysis of nonlinear behavior in idea of physical exercise with unification of mind and body," Journal of the Korea Institute of Electronic Cотmunication Sciences, vol. 11, no. 6, pp. 645-652, 2016. http://dx.doi.org/10.13067/JKIECS.2016.11.6.645 
[28] L. Huang, S. S. Hwang, and Y. Bae, "Chaotic behavior in model with a Gaussian function as external force," International Journal of Fuzzy Logic and Intelligent Systems, vol. 16, no. 4, pp. 262-269, 2016. http://dx.doi.org/10. 5391/IJFIS.2016.16.4.262

[29] Y. C. Bae, “Analysis of nonlinear behavior in love model as external force with Gaussian fuzzy membership function," Journal of Korean Institute of Intelligent Systems, vol. 27, no. 1, pp. 29-34, 2017. http://dx.doi.org/10.5391/ JKIIS.2017.27.1.029

[30] Y. C. Bae, "Nonlinear analysis in love dynamics with triangular membership function as external force," Journal of Digital Contents Society, vol. 18, no. 1, pp. 151-159, 2017.

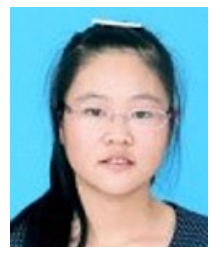

Linyun Huang received the Bachelor's degree in the department of Electronic Science and Technology from MinJiang University, FuJian, China. Since 2014, she has been a doctor course student in Department of
Biomedical and Electronic Engineering from Chonnam National University, Yeosu, Korea.

E-mail: hly911121@gmail.com

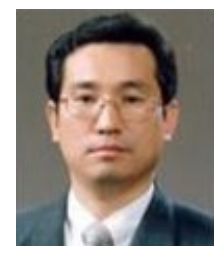

Youngchul Bae received his B.S. M.S., and Ph.D. from the Department of Electrical Engineering, Kwangwoon University, Korea, in 1984, 1985, and 1997, respectively. He worked at KEPCO (Korea Electric Power Company) during 1986-1991, and also worked at KISTI (Korea Institute of Science and Technology Information) during 19911997 as a Senior Researcher. He is currently a Professor at the Division of Electrical-Electronic Communication and Computer Engineering, Chonnam National University, Yeosu, Korea. His research interests include nonlinear dynamics, chaos dynamics, robot control, intelligent systems, and motor control. He is a member of KIEE, KIECS, and KIIS.

Tel: +82-61-659-7315, Fax: +82-61-659-7310

E-mail: ycbae@chonnam.ac.kr 